\title{
Simulation and Analysis of Small-Scale Solar Adsorption Cooling System for Cold Climate
}

\author{
Karolis Januševičius, Giedre Streckienė, and Violeta Misevičiūtė
}

\begin{abstract}
In the current study, research on the performance characteristics of an adsorption cooling system supplied by solar energy is presented. The main task for the analyzed system was to ensure cooling load for the non-residential building in cold climate country. A $8.0 \mathrm{~kW}$ adsorption thermal cooling system was studied. The system got heat produced by evacuated tube solar collectors. The parametric simulation study was carried using a TRNSYS (Transient Systems Simulation) program to determine the influence of various parameters on the system performance. The dependencies of collector slope and the total absorber area on solar fraction, discarded energy, coefficient of performance, seasonal performance factor were studied. The highest solar fraction, coefficient of performance and seasonal performance factor values were obtained if the collector slope was approximately 30 degrees and the absorber area was $16 \mathrm{~m}^{2}$ for the analyzed cases. The total primary energy consumption of the system was examined for various cases of primary energy factor for auxiliary heat and consumed electricity. On the basis of the results, it was proposed the expression of total primary energy consumption. The obtained results could be used for the recommendation preparations for decision makers to select a small scale solar cooling adsorption system.
\end{abstract}

Index Terms-Adsorption chiller, coefficient of performance, solar cooling, TRNSYS.

\section{INTRODUCTION}

Summer cooling is a growing market in buildings services. Increased living standards, occupants' comfort demands and building architectural trends (popular glass buildings) are the main reasons for the increasing energy demand for summer air cooling [1]. Cooling needs are higher in southern European countries. However, there is an increasing need for cooling in other countries too including northern Europe, particularly in office and commercial buildings. Solar energy can significantly contribute to prevent a drastic increase in conventional energy consumption for cooling and to reduce harmful emissions to the environment [2], [3].

The dominating technology in the European market of solar cooling installations is still absorption chillers. Although the coefficient of cooling efficiency of absorption cooler may have a higher value, especially with temperatures above $80^{\circ} \mathrm{C}$, a possibility of supplying the heating medium with a temperature lower than $70^{\circ} \mathrm{C}$ causes that among all of

Manuscript received February 25, 2014; revised May 13, 2014. This research was funded by a grant (No. ATE-03/2012) from the Research Council of Lithuania.

K. Januševičius, G. Streckienė, and V. Misevičiūte are with the Faculty of Environmental Engineering, the Department of Building Energetics, Vilnius Gediminas Technical University, Sauletekio ave 11, Vilnius, LT-10223, Lithuania (e-mail: karolis.janusevicius@vgtu.lt, giedre.streckiene@vgtu.lt, violeta.miseviciute@vgtu.lt). the available cooling systems supplied by solar energy, the adsorption refrigerating systems have been recognized as the most advantageous for cooling [3]-[5]. Adsorption chiller using silica gel-water adsorption pair, which could be powered by $60-85^{\circ} \mathrm{C}$ hot water, the cooling coefficient of performance (COP) is around $0.3-0.5$, the cooling capacity is usually 5-10 kW [6]-[9].

Significant development efforts are directed recently to solar cooling technologies based on adsorption systems driven by heat from solar thermal collectors. Hartmann et al. [10] made a comparison of solar thermal and solar electric cooling for a typical small office building exposed to two cities (Freiburg and Madrid). They found that main factors affecting the competitiveness of solar thermal cooling systems are the capacity utilization of the collector field, the occupancy scheme of the building (cooling demand), and the $\mathrm{COP}$ of the sorption machine. $\mathrm{Li}$ and $\mathrm{Wu}$ [11] made a theoretical research of an adsorption chiller in a micro combined cooling, heating and power system. They determined that the cooling capacity and the COP of the chiller are influenced significantly by the average value and variation rate of electrical load, as well as the average value of cooling load. It was showed that the water tank also had a great effect on the chiller performance [11].

Beccali et al. [12] carried out a detailed assessment of monitoring results of a solar desiccant evaporative cooling system in Italy. Monitoring results showed that the contribution of evaporative desiccant cooling effect achieved $53 \%$ of the total energy delivered by the air handling unit and the electric COP during summer operation was 2.4. Another study showed that adsorption cooling system can reduce the electricity consumption by $47 \%$ compared to a compression cooling system in an office building [13].

Solar thermal cooling systems are still in their infancy regarding practical applications, although the technology is sufficiently developed for a number of years [2]. Made studies show that the adsorption cooling systems still require significant research, development activities and practicability of these technologies [4]-[11], [14], [15]. It is a quite new topic if it comes to practical applications. Practical measurements show that low driving temperatures, the intermittent operation and less sunnier days have negative effects on the adsorption cooling system operation [15]. The performance of such kind of systems is strongly influenced by both cycle time and the allocation of the duration of the adsorption and desorption steps [16]. The mass recovery process has significant influence both on cooling capacity and COP [17]. Constructional and control oriented adaptations should be done in order to improve the existing systems' performance [18].

Non-domestic buildings such as institutional buildings 
contain different types of functional spaces which require different types of heating, ventilating and air conditioning (HVAC) systems. In addition, such buildings should maintain optimal comfort conditions with minimal energy consumption and minimal negative environment impact [19]. One of the main reasons to use thermal cooling system for non-domestic buildings is the cooling demand during the summer seasons for such buildings coincides with the solar energy gain [13].

Construction and use of adsorption refrigerating systems of low power, supplied by solar energy, is usually made for southern countries [2], [10], [15], [19], [20]. However, such applications still require deeper investigations in cold climate countries. In this study, a solar adsorption cooling system in a non-domestic building in cold climate is analyzed using TRNSYS 17 simulation software. A deeper analysis of the use of low power adsorption machine to obtain thermal comfort in rooms of the institutional building, relevant to external atmospheric conditions, has been executed. Therefore, the aim of this study is to investigate a solar-assisted adsorption cooling facility performance based on the cooling demand and the local meteorological data. A $8.0 \mathrm{~kW}$ adsorption thermal cooling system is analyzed for the institutional building.

\section{SOlAR AsSisted COOLING SYSTEM}

Research object is solar assisted cooling system. This system layout is based on laboratory of Building Energy and Microclimate Systems (BEMS). The analyzed system is a part of renewable energy system which supplies energy for space heating, cooling and electricity needs of laboratory space. The heat from solar collectors is supplied for adsorption chiller at typical summer conditions. Adsorption chiller supplies chilled water for laboratory space air conditioning needs. Solar produced heat could be directly used for supply air heating during cold period of the year.

The evacuated tube solar collectors of laboratory systems are analyzed. The total effective area of solar collectors is $9.8 \mathrm{~m}^{2}$. Collectors are shown in Fig. 1. There are ten evacuated tube solar collectors connected in a row. Water-propylene glycol mixture (33\%) is used as antifreeze and has influence on specific heat and density of heat transfer medium. Collected heat is stored in 500 liters storage tank. Storage tank is discharged by hydronic loop. The solar assisted cooling system with adsorption chiller is presented in Fig. 2.

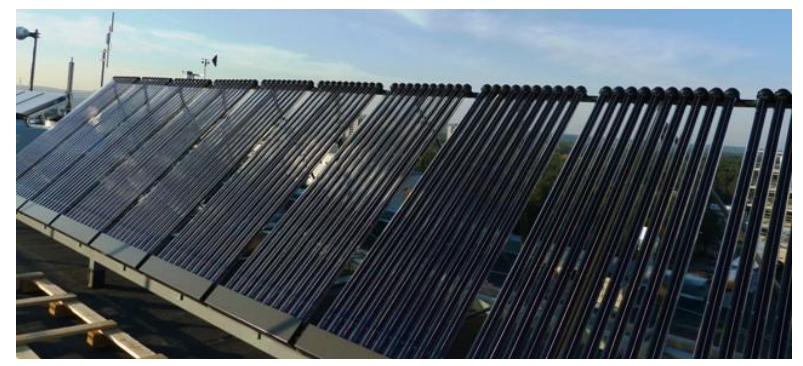

Fig. 1. The evacuated tube solar collectors of BEMS laboratory.

Adsorption cooling process needs stable heat supply of 55-95 C temperatures. Due to cooling machine efficiency dependence on supply temperature, it is appropriate to supply higher temperatures to maximize cooling output. The cooling system of BEMS laboratory is presented in Fig. 2. The analyzed system consists of evacuated tube solar collectors $\left(9.8 \mathrm{~m}^{2}\right)$, heat storage tank (500 l), auxiliary heater $(15 \mathrm{~kW})$, adsorption chiller $(8 \mathrm{~kW})$, cooling tower and cold storage tank (300 1).

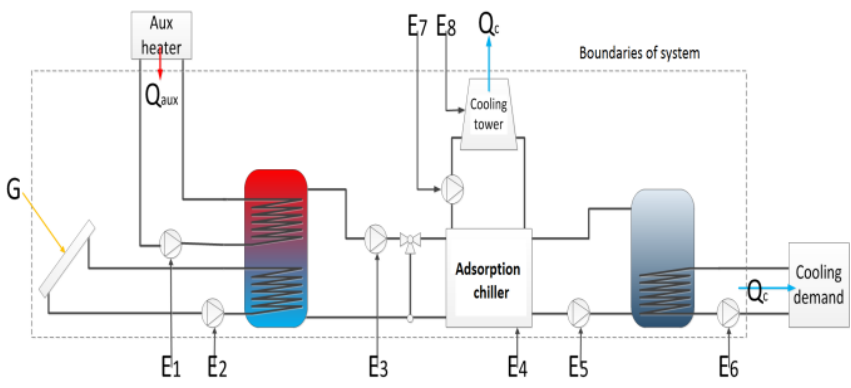

Fig. 2. Solar assisted cooling system with adsorption chiller.

The adsorption chiller and cold storage tank are presented in Fig. 3.

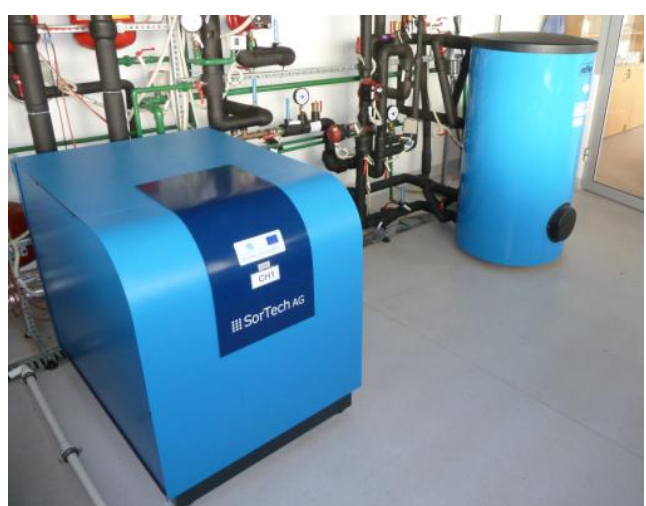

Fig. 3. Adsorption chiller and cold storage tank in laboratory technical room.

The hydraulic schema of BEMS laboratory systems (Fig. 2 ) is used for creating model of the thermal cooling system in TRNSYS.

\section{PERformance Evaluation}

The system performance was analyzed by estimating simulation results. The simulation was carried out from March $25^{\text {th }}$ to November $9^{\text {th }}$. The simulation time step was chosen $5 \mathrm{~min}$.

In order to evaluate system performance, the following performance criteria were involved in this study:

1) Solar fraction in the overall chilled water production $f_{\text {sol }}$.

2) Unutilized heat of solar collectors (the rate of energy discarded) $Q_{\text {surplus }}$.

3) Coefficient of performance of adsorption chiller $C O P_{c h}$.

4) Seasonal performance factor of overall system $S P F_{\text {sys }}$.

5) Primary energy consumption $E_{P E}$.

The percentage ratio of the thermal energy produced by solar collectors $\left(Q_{\text {sol }}\right)$ to the total needed cooling system energy $\left(Q_{c h . h}\right)$ is known as the solar fraction which can be expressed as (1)

$$
f_{\text {sol }}=\frac{Q_{\text {sol }}}{Q_{\text {ch.h }}} .
$$


The total needed cooling system energy consists of thermal energy generated from the solar collectors and the auxiliary heater. In this case, losses from heat storage and needed energy to cover them from auxiliary heater were not included into calculations. This ratio could be used to assess suitability of selected solar collectors parameters and their area.

Properly designed solar energy hot water system should fit the highest possible production rate with amount of needed heat to meet the demand. During the evaluation of collectors' area on the system performance, the appearance of high temperatures indicates the higher risk of the system stagnation. An additional calculation of an unutilized heat of solar collectors was performed. The rate of energy which is discarded to keep the fluid at the boiling point is shown in (2)

$$
Q_{\text {surplus }}=\dot{m} c_{p}\left(t_{\text {in }}-t_{\text {boil }}\right) .
$$

where, $\dot{m}$ represents flow rate, $c_{p}$ is the fluid specific heat, $t_{i n}$ is the inlet temperature ant $t_{\text {boil }}$ is the boiling point of fluid. TRNSYS Type13 was used for this evaluation.

The efficiency of a cooling system can be evaluated based on its COP. COP is the ratio between the cooling capacity required to supply air conditioning $\left(Q_{c}\right)$, and supply heat input needed for the adsorption chiller $\left(Q_{c h . h}\right)$. This parameter shows performance of the cooling chiller at simulated conditions and is defined as (3)

$$
C O P_{c h}=\frac{Q_{c}}{Q_{c h . h}} .
$$

Seasonal performance factor (SPF) expresses the overall system efficiency by taking all consumed electricity $(E)$ and produced cold energy $\left(Q_{c}\right)$ during the analyzed time period. Additionally, heat supplied by the auxiliary heater was included into calculations. $\mathrm{SPF}_{\text {sys }}$ can be expressed as (4)

$$
S P F_{s y s}=\frac{Q_{c}}{\sum E+Q_{c h . h} \cdot\left(1-f_{s o l}\right)} .
$$

A primary energy consumption criterion is selected to evaluate system's operational sustainability. Final energy consumed in the system was converted to the primary energy by using (5)

$$
E_{P E}=\sum\left(E_{x} \cdot f_{P E . E l}\right)+\sum\left(Q \cdot f_{P E . H}\right) .
$$

where, $E_{x}$ represents electricity consumed in the system elements, $Q$ is auxiliary heat supplied for the thermal cooling system.

Primary energy factor for electricity $\left(f_{P E . E l}\right)$ conversion was used. The minimum value of this factor could be low as 0.7 , when electricity from the renewable energy sources is used. The maximum value is 2.6 which specifies typical European electricity network. Due to high possible variation of primary energy factor for heat $\left(f_{P E . H}\right)$ supplied from auxiliary heater (from 0.1 for biomass to 2.6 for direct electricity) these factors are considered as variables for parametric analysis.

\section{TRNSYS MODEL}

TRNSYS is a transient system simulation program with a modular structure that was designed to solve complex energy systems problems by breaking the problem down into a series of smaller components known as Types [21].

\section{A. Description of System Model}

System consists of four main hydronic loops with circulation pumps (Fig. 4). Energy is transferred through loops by inducing mass flow rates according to control signals:

1) From solar collectors to hot storage tank;

2) From hot storage tank to adsorption chiller;

3) From adsorption chiller to cold storage tank;

4) From cold storage tank to demand side.

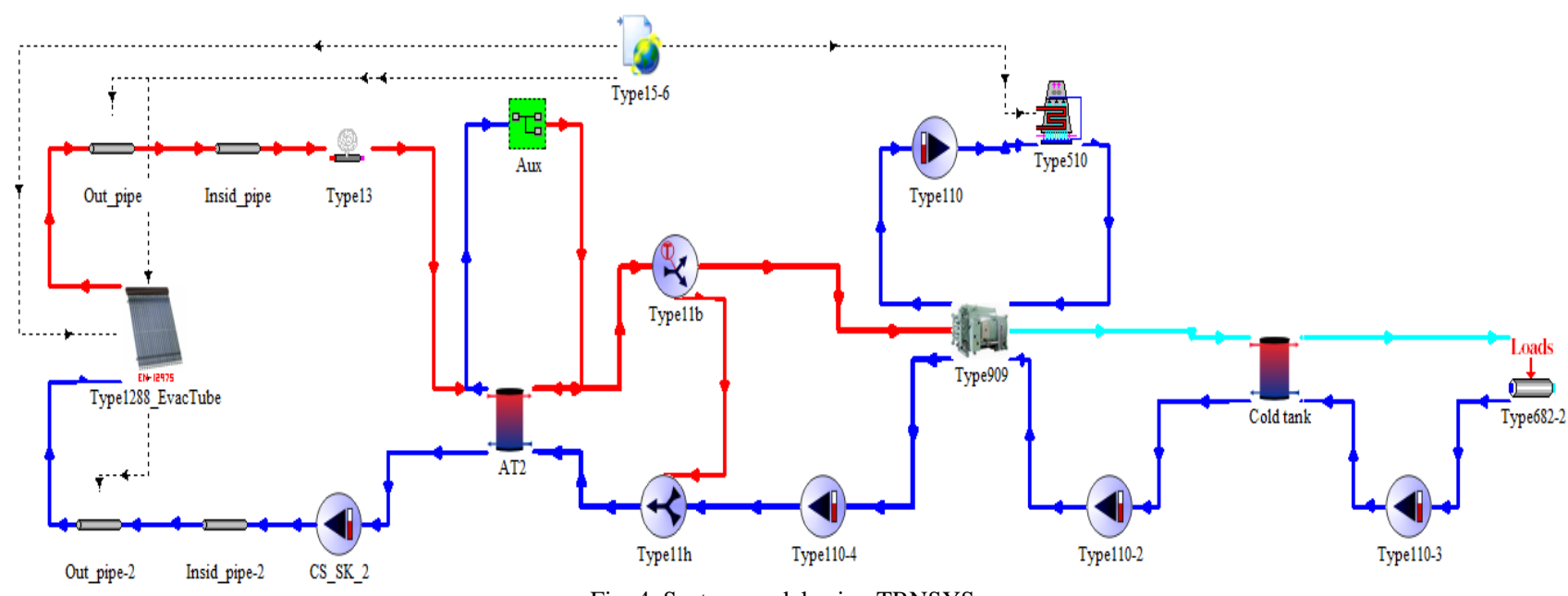

Fig. 4. System model using TRNSYS.

The controller switches the circulation pump on in solar collector loop when temperature difference between solar collector outlet and inlet of solar heat exchanger inside hot storage tank appears more than $3{ }^{\circ} \mathrm{C}$. Setpoint in cold storage tank is set to $7 \mathrm{C}$. Controller turns on cooling chiller and cooling tower when temperature rises more than $2{ }^{\circ} \mathrm{C}$ above setpoint.

Solar energy is harvested from the evacuated tube solar collectors and circulated in the primary water circuit to maintain its hot water temperatures. The harvested energy then transferred to the hot water storage tank through the immersed heat exchanger in hot storage tank. The second 
loop is used to deliver hot water from hot storage tank to the adsorption chiller, when controller turns on it. The third loop delivers cooled fluid to cold storage tank volume. The fourth loop discharges cold storage tank through immersed heat exchanger and delivers cooled fluid to demand side.

Auxiliary heater is needed to boost the hot water temperature when it falls below the system's driving temperature. The main components of the system are described below.

\section{B. Evacuated Tube Solar Collectors}

Evacuated tube solar collectors are modeled with Type 1288 which calculates dynamic efficiency as a function of inlet temperature can be obtained using Hottel Whillier (6)

$$
\eta=\eta_{0}-a_{1} \frac{\left(T_{i n}-T_{a m b}\right)}{I_{T}}-a_{2} \frac{\left(T_{i n}-T_{a m b}\right)^{2}}{I_{T}}
$$

where, $\eta_{0}$ is the optical efficiency, $a_{l}$ is the first order coefficient and $a_{2}$ is the second coefficient. $T_{\text {in }}$ is the water inlet temperature to the collector and $T_{a m b}$ is the ambient air temperature. $I_{T}$ is the total incident radiation on the collector per unit area.

In this study, the optical efficiencies of solar collectors for the first and second order coefficients were taken to be 0.85 , 1.38 and 0.0013 , respectively.

\section{Circulation Pumps}

There are modeled six circulation pumps (Type 110). Their powers and flow rates are respectively:

1) Solar collector loop: $83 \mathrm{~W}, 0.22 \mathrm{~kg} / \mathrm{s}$;

2) Heat storage tank discharge loop: $83 \mathrm{~W}, 0.28 \mathrm{~kg} / \mathrm{s}$;

3) Cold storage tank charge loop: $118 \mathrm{~W}, 0.28 \mathrm{~kg} / \mathrm{s}$;

4) Cooling tower loop: $173 \mathrm{~W}, 0.42 \mathrm{~kg} / \mathrm{s}$;

5) Auxiliary heater loop: $83 \mathrm{~W}, 0.28 \mathrm{~kg} / \mathrm{s}$;

6) Demand supply loop: $83 \mathrm{~W}, 0.33 \mathrm{~kg} / \mathrm{s}$.

\section{Thermal Energy Storage Tanks}

A stratified storage tank with 10 nodes is modeled (Type 534). The overall tank loss coefficient is assumed to be $0.75 \mathrm{~W} / \mathrm{m}^{2} \mathrm{~K}$ for hot storage tank and $0.5 \mathrm{~W} / \mathrm{m}^{2} \mathrm{~K}$ for cold storage tank, respectively. The fluid in the storage tank interacts with the fluid in the heat exchangers (through heat transfer with the immersed heat exchangers), with the environment (through thermal losses from the top, bottom and edges) and with flow stream that passes into and out of the storage tank. The storage tank is divided into isothermal temperature nodes. Each constant-volume node is assumed to be isothermal and interacts thermally with the nodes above and below through several mechanisms: fluid conduction between nodes, and through fluid movement.

\section{E. Auxiliary Heater}

Type 6 is auxiliary heater which elevates temperature of flow stream when temperature decreases below setpoint. It operates like an externally controlled ON/OFF heating device. Energy is delivered to the hot storage tank by immersed heat exchanger. The auxiliary heater has a heating capacity of $15 \mathrm{~kW}$ and the setpoint temperature is set to be $70{ }^{\circ} \mathrm{C}$.

\section{F. Adsorption Chiller}

Type 909 models an adsorption chiller; relying on performance data files containing normalized capacity and COP ratios as a function of the hot water, cooling water and chilled water inlet temperatures. Rated power of adsorption chiller is $8 \mathrm{~kW}$.

\section{G. Cooling Tower}

Type 510 models a closed circuit cooling tower. This device used to cool a liquid stream by evaporating water from the outside of coils containing the working fluid. The working fluid is completely isolated from the air and water in this type of system. Rated power of fan is $450 \mathrm{~W}$.

\section{H. Tempering Valve}

Type $11 \mathrm{~b}$ is used as a temperature controlled flow diverter to model a tempering valve. The setpoint temperature is selected to be $85 \mathrm{C}$.

\section{Pressure Relief Valve}

Thermal systems which employ a liquid (e.g. water) as a heat transfer medium typically include a pressure relief valve to discard the vapor (e.g. steam) if the liquid begins to boil. This component can be used to describe a pipe relief valve or a tank relief valve. Type 13 is used for this purpose.

Type 13 monitors inlet temperature, flow rate, and a comparison temperature. Energy is discarded whenever the comparison temperature is greater than the specified boiling temperature of the fluid. Loss of mass when the relief valve is open is assumed negligible. The outlet flow is always equal to the inlet flow rate. This amount of energy is presented as the analyzed parameter.

\section{J. Meteorological Data and Cooling Load}

The simulation is carried out using the Typical Meteorological Year (TMY) data bank from Meteonorm for Vilnius city. Type 15-6 was used in the model.

Building cooling load depends on many parameters like building orientation, building size, gain, ventilation, infiltration and climatic conditions [22].

Cooling load used in simulation was generated by Type 686 as synthetic demand based on defined peak load and modifying sine-wave functions used to account for seasonal variations, time-of-day variations and weekday/weekend differences. This model represents a quick method of providing realistic loads without the time-intensive modeling required for a real building.

Using synthetic loads, various cooling profiles could be determined. This helps to imitate different building behaviors. Short cooling season with high peak loads could represent energy efficient building with passive cooling demand reduction solutions, whereas long cooling season with high peak load imitates highly glazed facades.

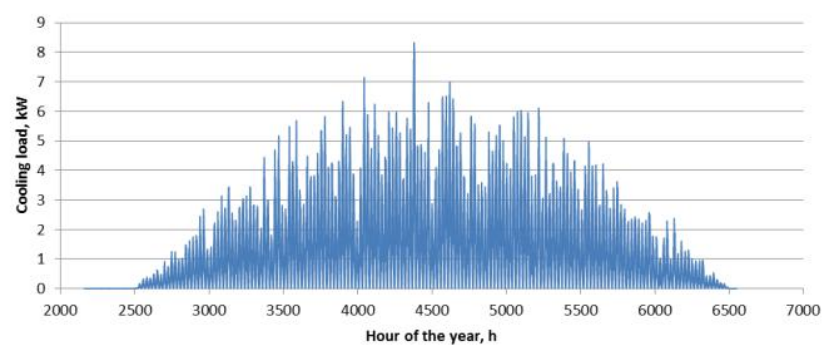

Fig. 5. Cooling load profile. 
The cooling load profile generated by Type 686 is presented in Fig. 5.

The design peak cooling capacity of $8 \mathrm{~kW}$ was estimated and used for cooling load characterization. This parameter was used to analyze following operational parameters of the system.

The total annual cooling demand was $3375 \mathrm{kWh}$ during 4000 hours cooling season. It reached its peak in the month of July.

\section{RESULTS AND DisCUSSION}

In this section, the simulation results of the solar assisted cooling system are presented. Analyzed results represent the sum of integrated values for the whole cooling season. Simulation time step is 5 minutes.

The effect of changing collector's area and inclination angle on solar fraction is presented in Fig. 6. The system solar fraction is increasing when the area of absorber increases. The biggest solar fraction value for cooling season is obtained if the collector slope is approximately 30 degrees and the absorber area is $16 \mathrm{~m}^{2}$ for the analyzed cases.

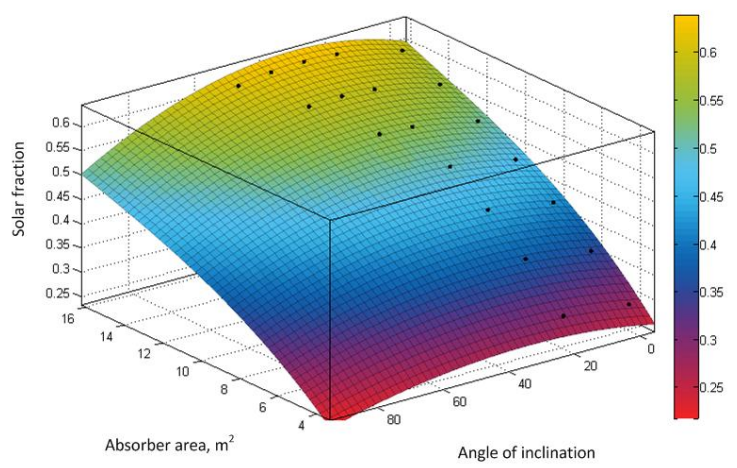

Fig. 6. Effect of changing collector's area and inclination angle on solar fraction.

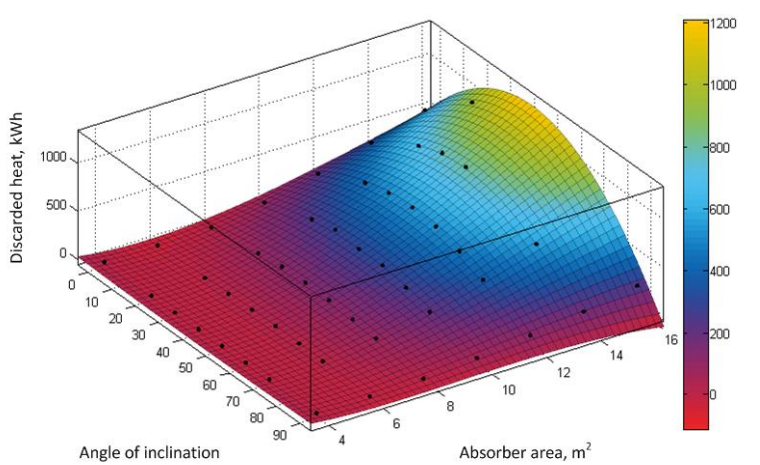

Fig. 7. Effect of changing collector's area and inclination angle on discarded energy.

The effect of changing collector's area and inclination angle on discarded energy is presented in Fig. 7. As can be seen from Fig. 7, discarded heat has the parabolic dependency on absorber area and inclination angle of the collector. For the analyzed case, if the absorber area is in range from $4 \mathrm{~m}^{2}$ to $8 \mathrm{~m}^{2}$ it was determined that the discarded energy is almost constant at different inclination angles of solar collector.

The discarded energy rate is directly related to solar fraction and it has exponential dependency. The highest discarded energy rate is obtained when the solar fraction is 0.6 .

The thermal efficiency of adsorption chiller can be quantified by using COP. Fig. 8 shows the dependency of the $\mathrm{COP}$ on collector area and inclination angle of analyzed system. The results have shown that the dependency of COP has polynomial surface. The COP is changing slightly, approximately only $1 \%$ for analyzed range.

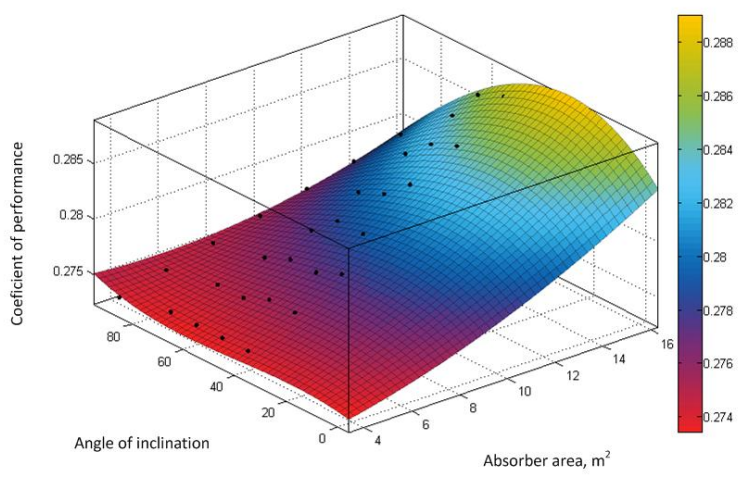

Fig. 8. The dependence of the COP on collector's area and inclination angle.

The effect of changing collector's area and inclination angle on SPF of system is presented in Fig. 9. Calculated SPF value is higher than $\mathrm{COP}$ of the adsorption chiller.

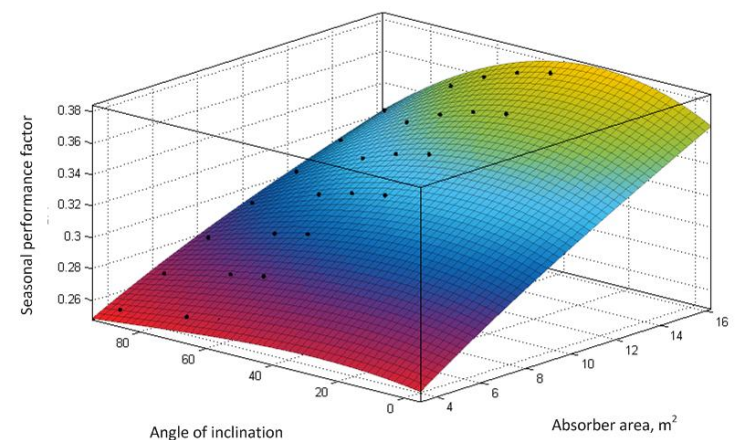

Fig. 9. The dependence of the system SPF on collector's area and inclination angle.

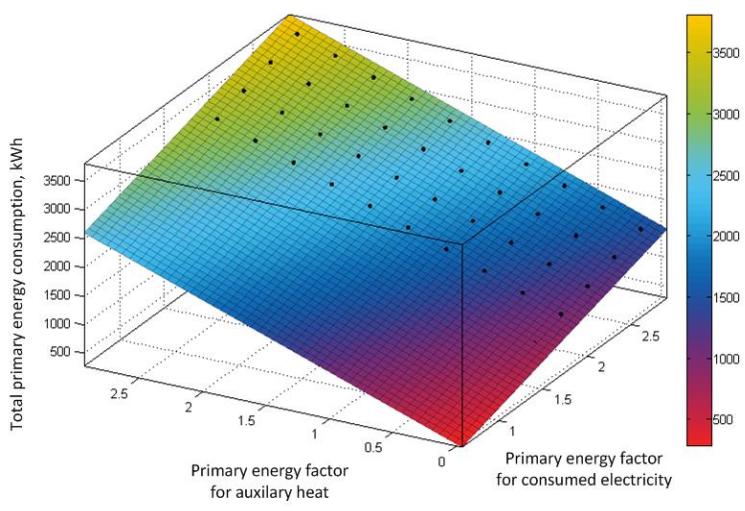

Fig. 10. Variation of total primary energy consumption.

It happens due to calculation method, when denominator is reduced by heat supplied by solar collectors and energy consumed in fans and circulation pumps was added in calculations. The relation of SPF to absorber area is almost linear. The highest values of COP and SPF are reached when 
the inclination angle of the collector is approximately 30 degrees.

The total primary energy consumption of the system is presented in Fig. 10. This figure shows an influence of primary energy factors on total primary energy consumption.

In many EU countries building energy rating procedure takes primary energy consumption as measure of energy performance and sustainability. When building demands and loads are known, simplified methods could be used for system concept selection and comparison with typical refrigerant cooling systems.

System parameters, characterizing main design assumptions and cooling demand must be known:

1) cooling demand $\left(Q_{C}\right)$ - could be determined according to methods like EN ISO 13790;

2) cooling capacity $\left(P_{C}\right)$ - determined by transient or quasi-steady state methods;

3 ) duration of cooling season $\left(\tau_{C}\right)$ - determined according to EN ISO 13790;

4) adsorption machines efficiency $(C O P)$ - at rated condition;

5) inclination angle of solar collectors $(\varphi)$ - as design assumption;

6) absorber area of evacuated tube solar collectors $\left(A_{S C}\right)-$ as design assumption;

7) total rated power of circulation pumps and cooling tower fan $\left(W_{\text {rated }}\right)$.

Total primary energy consumption could be expressed as (7):

$$
\begin{aligned}
& E_{P E}=\left(\frac{Q_{C}}{C O P} \cdot\left(1-f_{s o l}\left(A_{S C} ; \varphi\right)\right)\right) \cdot f_{P E . H}+ \\
& +\left(\sum W_{\text {rated }} \cdot a\left(P_{C} ; \tau_{C}\right)\right) \cdot f_{P E . E l} .
\end{aligned}
$$

Suggested correlation function based on simulation results, when zone cooling capacity and cooling season duration are known, is determined as (8)

$$
a=3956-18.67 \cdot P_{C}-0.0268 \cdot \tau_{C} .
$$

Suggested expression (9) of solar fraction when inclination angle and absorber area are predicted follows

$$
\begin{aligned}
& f_{\text {sol }}=0,1065+0.04832 \cdot A_{S C}+0.001943 \cdot \varphi- \\
& -0.001074 \cdot A_{S C}{ }^{2}-3,324 \cdot 10^{-5} \cdot A_{S C} \cdot \varphi- \\
& -2.619 \cdot 10^{-5} \cdot \varphi^{2}
\end{aligned}
$$

Usage of these suggested formulas are limited to single cooling unit system with typical evacuated tube collectors in climate similar to Lithuania.

\section{CONCLUSION}

In this study, a solar assisted cooling system in non-residential building was evaluated using TRNSYS 17 simulation software. The study outlined the potential of using a solar assisted cooling system under cold climate. The proposed system consists of an adsorption chiller, evacuated tube solar collectors, heat and cold storage tanks. A TRNSYS model was simulated using a typical meteorological year. The system's technical performance was evaluated. Furthermore, this study investigated the factors that affect the performance of a solar assisted cooling system like different solar collector's areas and inclination angle.

The obtained results could be used for preparation of the recommendations for developers and decision makers to select small scale solar assisted cooling system. Furthermore systems' economical evaluation should be made for more rational system selection.

\section{ACKNOWLEDGMENT}

This research was funded by a grant (No. ATE-03/2012) from the Research Council of Lithuania.

\section{REFERENCES}

[1] X. Q. Zhai and R. Z. Wang, "Experimental investigation and performance analysis on a solar adsorption cooling system with/without heat storage," Applied Energy, vol. 87, pp. 824-835, 2010 .

[2] T. Mateus and A. C. Oliveira, "Energy and economic analysis of an integrated solar absorption cooling and heating system in different types and climates," Applied Energy, vol. 86, pp. 949-957, 2009.

[3] R. Sekret and M. Turski, "Research on an adsorption cooling system supplied by solar energy," Energy and Buildings, vol. 51, pp. 15-20, 2012.

[4] A. A. Askalany, M. Salem, I. M. Ismael, A. H. H. Ali, M. G. Morsy, and B. B. Saha, "An overview on adsorption pairs for cooling," Renewable and Sustainable Energy Reviews, vol. 19, pp. 565-572, 2013.

[5] M. Jradi and S. Riffat, "Tri-generation systems: Energy policies, prime movers, cooling technologies, configurations and operation strategies," Renewable and Sustainable Energy Reviews, vol. 32, pp. 396-415, 2014.

[6] R. Z. Wang, T. S. Ge, C. J. Chen, Q. Ma, and Z. Q. Xiong, "Solar sorption cooling systems for residential applications: Options and guidelines," International Journal of Refrigeration, vol. 32, pp. 638-660, 2009.

[7] R. Z. Wang, "Efficient adsorption refrigerators integrated with heat pipes," Applied Thermal Engineering, vol. 28, pp. 317-326, 2008.

[8] J. Deng, R. Z. Wang, and G. Y. Han, "A review of thermally activated cooling technologies for combined cooling, heating and power systems," Progress in Energy and Combustion Science, vol. 37, pp. 172-203, 2011.

[9] Y. L. Liu, R. Z. Wang, and Z. Z. Xia, "Experimental study on a continuous adsorption water chiller with novel design," International Journal of Refrigeration, vol. 28, pp. 218-230, 2005.

[10] N. Hartmann, C. Gluecka, and F. P. Schmidt, "Solar cooling for small office buildings: Comparison of solar thermal and photovoltaic options for two different European climates," Renewable Energy, vol. 36, pp. 1329-1338, 2011.

[11] S. Li and J. Y. Wu, "Theoretical research of a silica gel-water adsorption chiller in a micro combined cooling, heating and power (CCHP) system," Applied Energy, vol. 86, pp. 958-967, 2009.

[12] M. Beccali, P. Finocchiaro, and B. Nocke, "Energy performance evaluation of a demo solar desiccant cooling system with heat recovery for the regeneration of the adsorption material," Renewable Energy, vol. 44, pp. 40-42, 2012.

[13] L. F. Sim, "Numerical modelling of a solar thermal cooling system under arid weather conditions," Renewable Energy, pp. 1-6, 2013.

[14] N. Enteria and K. Mizutani, "The role of thermally activated desiccant cooling technologies in the issue of energy and environment," Renewable and Sustainable Energy Reviews, vol. 15, pp. 2095-2122, 2011.

[15] S. Thomas, S. Hennaut, S. Maas, and P. Andre, "Experimentation and simulation of a small-scale adsorption cooling system in temperate climate," Energy Procedia, vol. 30, pp. 704-714, 2012.

[16] A. Sapienza, S. Santamaria, A. Frazzica, and A. Freni, "Influence of the management strategy and operating conditions on the performance of an adsorption chiller," Energy, vol. 36, pp. 5532-5538, 2011.

[17] Z. S. Lu and R. Z. Wang, "Study of the new composite adsorbent of salt $\mathrm{LiCl} /$ silica gel-methanol used in an innovative adsorption cooling 
machine driven by low temperature heat source," Renewable Energy, vol. 63, pp. 445-451, 2014.

[18] I. Daßler and W. Mittelbach, "Solar cooling with adsorption chillers," Energy Procedia, vol. 30, pp. 921-929, 2012.

[19] A. M. Baniyounes, G. Liu, M. G. Rasul, and M. M. K. Khan, "Analysis of solar desiccant cooling system for an institutional building in subtropical Queensland, Australia," Renewable and Sustainable Energy Reviews, vol. 16, pp. 6423-6431, 2012.

[20] P. J. Martinez, J. C. Martinez, and M. Lucas, "Design and test results of a low-capacity cooling system in Alicante (Spain)," Solar Energy, vol. 86, pp. 2950-2960, 2012.

[21] S. A. Klein et al., A Transient System Simulation Program (TRNSYS 17) Manual,Thermal Energy System Specialists. Madison, USA, 2010

[22] T. Tsoutsos, E. Aloimpi, Z. Gkouskos, and M. Karagiorgas, "Design of a solar absorption cooling system in a Greek hospital," Energy and Buildings, vol. 42, pp. 265-272, 2010.

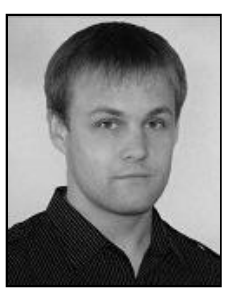

Karolis Januševičius was born in Šiauliai on Augus 2, 1988. He got his M. Sc. degree in thermal engineering at Vilnius Gediminas Technical University (VGTU) in 2013. He is a PhD student of mechanical engineering at VGTU.

He has been certified as a passive house designer at 2012. His current research interests are mechanical systems for "Passivhaus" and renewable energy system combinations. $\mathrm{He}$ is an author of 7 publications. His previously published works contain investigation studies about heat capacity determination in energy efficient houses and solar assisted heat pump examinations for near zero energy building.

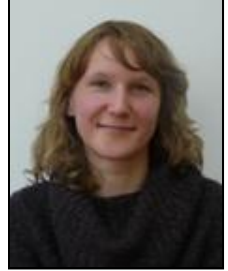

Giedrė Streckienė was born in Vilnius on November 12, 1981. She got her M. Sc. degree in energetics and power engineering at Vilnius Gediminas Technical University (VGTU) in 2006. Her PhD thesis "Research of heat storage tank operation modes in cogeneration plant" was defended in VGTU (2011). Her main research area is cogeneration and thermal energy storage technologies.

She is an assoc. professor at VGTU Department of Building Energetics. She has been part of academic staff of Faculty of Environmental Engineering, VGTU since 2006. She is an author of 17 scientific publications.

Dr. Streckienè has participated in international and national projects.

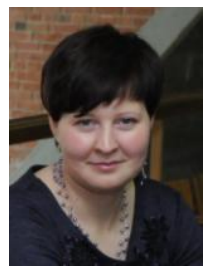

Violeta Misevičiūtè was born in Trakai on August 4, 1983. She got her M.Sc. degree in energetics at Vilnius Gediminas Technical University (VGTU) in 2007. Her $\mathrm{PhD}$ thesis "Evaluation of possibilities for processes integration in ventilation equipment" was defended in VGTU (2012). Her main research area is efficiency use of energy in building engineering systems.

She is an assoc. professor at VGTU Department of Building Energetics. She is an author of 12 scientific publications.

Dr. Misevičiūte has participated in international project related to building refurbishment and national project. 